\title{
Market Efficiency and Technical Analysis in Romania
}

\author{
Dan Gabriel Anghel ${ }^{1}$ \\ ${ }^{1}$ Department of Money and Banks, Faculty of Finance, Insurance, Banking and Stock Exchange, The Bucharest \\ University of Economic Studies, Bucharest, Romania \\ Correspondence: Dan Gabriel Anghel, Associate Lecturer, Department of Money and Banks, Faculty of Finance, \\ Insurance, Banking and Stock Exchange, The Bucharest University of Economic Studies, Bucharest, Romania. \\ E-mail: dan.anghel@fin.ase.ro
}

Received: March 5, 2015

Accepted: April 3, 2015

Online Published: April 17, 2015

doi:10.5430/ijfr.v6n2p164

URL: http://dx.doi.org/10.5430/ijfr.v6n2p164

\begin{abstract}
In this paper we make a detail evaluation of stock market efficiency in Romania. First, we employ 686,243 trading models derived from 44 technical analysis indicators and determine that significant inefficiencies exist for stock prices in this country. The time varying nature of these points out that market efficiency is not improving over time, but instead fluctuates in the way consistent to the Adaptive Market Hypothesis. We show that investor success does not depend on the target investment asset, slightly depends on specific prediction models and heavily depend on the size of the implemented rule universe. Next, we focus on finding out what are the determining factors for market efficiency. Contrary to what one might expect, we find that market liquidity has an almost insignificant impact on efficiency. The main determining factor for market efficiency in Romania is price momentum, and argues that the detected anomalies are due to investor behavioral biases.
\end{abstract}

Keywords: adaptive market hypothesis, bootstrap, efficient market hypothesis, Romanian stock market, superior predictive ability, technical analysis

\section{Introduction}

Since escaping from the communist influence at the beginning of the 1990's, Romania has become one of the biggest economies in Central and Eastern Europe. Its stock market has also grown and modernized tremendously, but has somehow failed to keep pace with the rest of the economy, mainly due to the lack of investment culture in the country. The two big financial and economic crisis, a local one in the second part of the 1990's and the global one that began in 2007 and is still not over, plus several fraud scandals that have stunned the financial markets have not helped either. On the plus side, the integration into the European Union and the commitment towards adopting the Euro have attracted more mature foreign investors that encouraged the development of the local stock market through their financial and human capital. The main charm for all investors was the severely underpriced companies that could have been found listed on the market at the time, as pointed out by Dragotă, Căruntu and Stoian (2008). There are two things that can be deducted from this consistent historical mispricing. First, that back then the Romanian stock market was not informationally efficient and secondly, that substantial abnormal returns could be gained from investing in it. As a consequence, the prices rised substantially, and is fair to say that there is no evident mispricing present in the market at the moment. But has the market become informationally efficient in the meantime? Do opportunities to gain abnormal profits still exist? And if so, how would an investor achieve this? Also, what are the determining factors for market efficiency in Romania? These are all unanswered questions that this paper tries to answer by investigating the predictive ability of 44 technical analysis indicators.

Several authors (see, for example, Dragotă et. al, 2009) have investigated if the Romanian stock market is efficient or not using classical econometric tests, like autocorrelation, unit root, variance ratio and so on, but have not reached a consensus as to the efficient nature of the local market. There are also a few authors (see, for example, Anghel, 2013a, 2013b) that have investigated the profitability of technical analysis indicators trough out of sample tests performed on optimized trading rules and have drawn conclusions about informational efficiency from them. Dragotă and Oprea (2014) provide an extensive review in this sense. They point out that the dominating trend is in favor of an improving efficiency for the Romanian stock market in the recent years. But is it truly so? The problem with the first category of tests is that they are severely unpractical. Lim and Brooks (2011) point out that "proponents of the EMH always dismiss negative empirical evidence on the grounds that those detected stock market predictable patterns do not give 
rise to profitable investment strategies". Adopting a technical analysis framework that we know actual investors use, should mitigate this criticism. The problem with the second category of papers is that there are still very sparse and are based on relative simple tests, so there is much potential for improvement and, consequently, for significant discoveries. This study tries to compensate these deficiencies by employing a new approach and increasing the quantity and quality of tested elements. There are substantial contributions made here. First, a total of 44 different technical analysis indicators, combined in 5 different investment strategies, which yield 686,243 trading rules, are tested and analyzed. This is far more than any study has done before, even by international standards (details are provided below). Second, the Superior Predictive Ability test (SPA from now on) of Hansen (2005) is employed as the testing method. This is a modern econometrical test based on the bootstrap simulation that was design specifically for this kind of applications and has never been used before on the Romanian market. Third, the test is performed in a consecutive window approach, which means that distinct time intervals are analyzed separately. With each window representing one full year of trading data, it enables us to draw conclusions about the time varying nature of market efficiency. The remainder of the paper is organized as follows: section 2 details on the methodology and the data involved, section 3 presents the results and comments on them, while section 4 concludes.

\section{Methodology}

Before going into the methodological details, several implemented rules and restrictions need to be mentioned, these being also employed by Anghel (2013a, b), which offers detailed explanations regarding their importance. First, because of existing market restraints on short selling, only long trades are taken into account. Second, all trades are performed with a one day delay after a trading signal has occurred. Third, it is assumed that $100 \%$ of the portfolio is invested in the market when opening new positions. Fourth, because only economic returns are sought, the results are adjusted to trading costs. The broker fee is set to $0.5 \%$ of traded value, this being an average cost of trading in this market in the period (actual fees range from about $0.2 \%$ for big institutional investors to $1 \%$ for small retail investors, with an exceptional fee of $4-8 \%$ for coupon investors that wish to cash in their shares). Also, the bid-ask spread cost and price impact cost are deducted when trading using the High-Close and Close-Low spreads as proxies.

Another significant restriction is implemented when creating the rule universe from individual rule templates, specifically all window length parameters of the technical analysis rules are restricted to a maximum of 43 observations, this roughly equaling two months of trading data. Finally, the benchmark is chosen as the buy-and-hold strategy because this is the natural trading strategy for an informationally efficient market. Also, in order to evaluate the time-dependent nature (if one exists) for market efficiency, a consecutive window approach is undertaken, with each year of trading data constituting one subsample window.

\subsection{Trading Strategies}

In essence, technical analysis indicators are models that make one-step-ahead predictions of the direction and/or strength of price movements. There are two types of technical analysis indicators tested here, specifically momentum indicators and money flow indicators (Note 1). There are three basic ways in which one could use these kinds of indicators, these being detailed in Table 1.

Table 1. Trading strategies for momentum and money flow indicators

\begin{tabular}{|c|c|c|}
\hline No. & Label & Description \\
\hline 1 & "momentum" & $\begin{array}{l}\text { In a trend following strategy that tracks the momentum direction and keeps an } \\
\text { open position in favor of the current momentum. }\end{array}$ \\
\hline $\begin{array}{r}2 \\
\text { and }\end{array}$ & $\begin{array}{l}\text { "vs. Signal" } \\
\text { and } \\
\text { "vs. Delay" }\end{array}$ & $\begin{array}{l}\text { In a counter-trend strategy that tracks the rate of change of the momentum } \\
\text { and opens a trade when the indicator value intersects a predefined "signal" } \\
\text { line. Here, using an exponential moving average of the indicator as a signal } \\
\text { yielded the } 2 \text { nd strategy, while using a simple n-period delay of the actual } \\
\text { indicator yielded the } 3 \text { rd strategy. }\end{array}$ \\
\hline $\begin{array}{r}4 \\
\text { and } \\
5\end{array}$ & $\begin{array}{l}\text { "oversold I" } \\
\text { and } \\
\text { "oversold II" }\end{array}$ & $\begin{array}{l}\text { In a counter-trend strategy that looks for unusual (extreme) momentum levels. } \\
\text { Here, the 4th strategy means that open positions are closed when the } \\
\text { indicators move away from the extreme that initiated the position, while the } \\
\text { 5th strategy closes the positions when the opposite extreme is reached. }\end{array}$ \\
\hline
\end{tabular}


Each of the technical analysis indicators is combined with at least one strategy mentioned in Table 1 to generate trading rule templates. These rule templates have one or more parameters, and when values are assigned to them, actual trading rules are generated. All trading rules take the form of a comparison statement between the values of two functions, with the first representing the technical analysis indicator and the second representing either a smoothening function for the indicator or a constant. When the statement is true, it signifies that a long position should be opened, otherwise no position should be opened.

\subsection{Technical Analysis Indicators}

There are 44 technical analysis indicators used to construct template trading rules. These are listed in table 5, when reporting the results for each one. The reader is highly encouraged to follow Colby (2002) for details on their conception, number of parameters, interpretation and usage. Numerous articles that present the indicators can nowadays also be found online, with just a simple search. The goal of this paper is to examine the predictive ability of specific trading rules constructed using these technical analysis indicators, or, in other words, to examine if they are capable of generating abnormal stock market returns. Any evidence in this sense would be in contradiction to the weak form EMH in Romania.

Overall, by combining the 44 indicators with their corresponding trading strategies, 171 template treading rules are generated. By iterating through the possible parameter combinations, a total number of 686,243 actual trading rules are produced. This is the complete rule universe that is used in order to search for abnormal profits on stocks listed on the Romanian stock market.

When using a rule universe as diverse as this, it is assumed that we are looking at what a sophisticated investor might gain in his/her investment activity. But it is very interesting to also find out what limited investors might achieve. This kind of investors usually use only one indicator to guide them in their decisions. Thus, separate trading universes formed by using the trading rules derived from a single indicator are also considered and tested independently. This means that a total of 44 smaller rule universes are also analyzed, together with the complete $600+$ thousand-object one. Making an analogy from astronomy, if the 686,243 objects make up the full universe, then 44 separate galaxies are also studied.

\subsection{Testing Methodology}

The SPA test of Hansen (2005) is the methodology employed in order to evaluate the predictive ability of the trading rules. The test is an improved Reality Check (RC from now on), developed by White (2000). It tests for the null hypothesis that the best model encountered during a specification search has no predictive superiority over a benchmark model. In other words, the test rejects the null if at least one predictive model from the candidate universe, in this case a trading rule, possesses superior predictive ability over the benchmark model. The test procedure delivers asymptotically appropriate $\mathrm{p}$-values for the null hypothesis by seeking to control the simultaneous rate of error. This test was especially constructed for applications such as searching for a trading rules that generates abnormal returns with a large candidate universe in mind, these kind of application being very susceptible to data snooping biases.

Other tests that search for superior predictive ability exist in the literature but they are not computationally efficient. The RC is a huge step forward from those and also from tests that focus on evaluating if two models have the same predictive power. Since White published this method, several other significant tests have been developed to tackle this kind of applications, among which is the SPA. Hansen introduced two improvements over the RC, specifically the studentization of the test statistic and the removal of very poor alternative models from the calculations. He demonstrated that these adjustments lead to the SPA test being more powerful and less sensitive to irrelevant alternatives than the RC. Going forward, Romano and Wolf (2005) introduced a stepwise version of the RC that is capable of detecting all superior models, not just the best one as it is done with the RC. Hsu, Hsu and Kuan (2010) extended Hansen's test to a stepwise SPA test, combining the benefits of the stepwise procedure with the improved statistics suggested by Hansen. Corradi and Swanson (2013) provide a detailed review of available tests in similar applications and also suggest a new alternative in which they focus on controlling the overall error rate.

The SPA was adopted here because the increased power makes it the preferred test when choosing between it and the RC. Also, we are only interested in finding one specific trading rule that is capable of generating abnormal returns, because such a discovery is sufficient to reject the weak form EMH, thus being sufficient for the researcher in this field.

As is the RC, the SPA test relies on the stationary bootstrap of Politis and Romano (1994), with blocking rules derived from Hall, Horowitz and Jing (1995). Using Hansen's (2005) original notations, the SPA test procedure 
unfolds as follows. Taken a series of $\mathrm{m}$ binary h-step-ahead prediction models (for technicala analysis indicatorors, $h$ $=1)$ grouped into a rule universe $\left\{\delta_{k, t h}, k=0,1 \ldots m\right\}$ and a given return series $\left\{\zeta_{t}, t=1 \ldots T\right\}$ the following loss function can be implemented to calculate the performance of model $\mathrm{k}$ :

$$
L\left(\zeta_{t}, \delta_{k, t-1}\right)=-\delta_{k, t-1} \zeta_{t}
$$

Note the benchmark buy and hold model used here is defined as $\delta_{0, t}=1$, while $m=686,243$ (the total number of trading rules). Next, the excess performance is calculated and stored in the variable $d_{t}=\left(d_{1, t} \ldots d_{m, t}\right)^{\prime}$ :

$$
d_{k, t} \equiv L\left(\zeta_{t}, \delta_{0, t-1}\right)-L\left(\zeta_{t}, \delta_{k, t-1}\right), \quad k=1 \ldots m
$$

Provided that $\mu \equiv E\left(d_{t}\right)$ is the mean excess performance, the SPA null hypothesis is formulated as $H_{0}: \mu \leq 0$. In order to test the null, the following statistic is used:

$$
T_{n}^{S P A} \equiv \max \left\lceil\max _{k=1 \ldots m} \frac{n^{1 / 2} \bar{d}_{k}}{\widehat{\omega}_{k}}, 0\right\rceil
$$

where $\omega^{2}{ }_{k} \equiv \operatorname{var}\left(n^{1 / 2} d_{k}\right)$ is a consistent estimator of the variance of the excess performance. To eliminate the influence of very poor alternative models from the universe, Hansen uses the following consistent estimator for the mean relative performance:

$$
\hat{d}_{k}^{c}=\bar{d}_{k} 1_{\left\{\frac{n^{1 / 2} \bar{d}_{k}}{\widehat{\omega}_{k}} \leq-\sqrt{2 \log \log n}\right\}}
$$

where $1_{\{.\}}$denotes the indicator function and the $c$ superscript denotes that the estimator is based on the recentered null distribution. The practical calculation of the test statistic involves the construction of the pseudo time-series $\left\{d_{b, t}^{*}\right\} \equiv\left\{d_{\tau b, t}, b=1 \ldots B\right.$, which are resamples of $\mathrm{d}_{\mathrm{t}}$ using the Politis and Romano (1994) stationary bootstrap procedure. Based on that, the sample average is calculated as $\bar{d}_{b}^{*} \equiv n^{-1} \sum_{t=1}^{n} d_{b, t}^{*}$ and the sample variance is calculated as $\widehat{\omega}_{k, B}^{* 2} \equiv B^{-1} \sum_{b=1}^{B}\left(n^{1 / 2} \bar{d}_{k, b}^{*}-n^{1 / 2} \bar{d}_{k}\right)^{2}$. In the final version of the paper, Hansen recommended another variance estimator based directly on the bootstrap-population value, but that is not implemented here as the number of simulations is sufficiently large $(B=1000)$ in order to reduce the additional layer of randomness that is introduced by the resampling scheme. Next we calculate the test statistic using equation 3 , and its empirical distribution using the following equation:

$$
T_{b, n}^{S P A *}=\max \left\{0, \max _{k=1 \ldots m}\left[n^{1 / 2} \bar{Z}_{k, b}^{*} / \widehat{\omega}_{k}\right]\right\}
$$

where $Z^{*}{ }_{k}$ is the empirical distribution of the test statistic of model $\mathrm{k}$ obtained from the B bootstrap resamples. Finally, the SPA p-value can be calculated as:

$$
\hat{p}_{S P A} \equiv \sum_{b=1}^{B} \frac{{ }^{1}\left\{T_{b, n}^{S P A *}>T_{n}^{S P A}\right\}}{B}
$$

For more details regarding the test's formulation, properties and theoretical implications, please see Hansen's (2005) paper. The main goal of this investigation is to use the SPA in order to discover for each year and for each company included in the sample if specific trading rules have superior predictive ability over the benchmark buy and hold model. We name the event when the SPA null is rejected as a "positive discovery", because it rejects the weak form EMH for the company and time frame on which the test was carried out.

There is, however, another very important secondary goal to this paper, namely explaining why the market behaves inefficiently when it does? In order to answer this question, note in equation 6 that the SPA p-value is roughly the inverse percentile at which the SPA test statistic (calculated for the best trading rule in the universe) is found within its empirical distribution (determined using the maximum outputs of the bootstrap simulation). This leads to a natural association between the SPA p-value and the predictive ability of the best model in the trading rule universe. When the p-value is large, then the best model has no predictive ability. The smaller the p-value, the greater the predictive ability of the best model in the universe. When the p-value is close to zero, then we have superior predictive ability, meaning that the best model in the universe has some economic use. Here, a threshold of 0.1 is used to identify superior predictive ability rules (so weak statistical significant results are also taken into consideration). Because the degree of predictive ability of technical analysis indicators has a direct and negative relationship with market efficiency, a natural way of studying the latter is now derived. All we have to do is to search for factors that influence 
the SPA p-value so we can determine what variables have an influence on stock market efficiency. So the secondary goal is to use the test results and to try to explain what influences the degree of market efficiency in Romania.

Note that all the calculations are performed using our own implementation in C\#. Code samples may be provided on request.

\subsection{Data Sample}

The data is collected using Thompson Reuters Eikon. All available price and volume data up to November 14, 2013 is retrieved for 39 companies listed on the Bucharest Stock Exchange, the main stock market in Romania (Note 2).

Sample windows with less than 65 days of trading data are eliminated because of insufficient liquidity. This boundary is chosen rather arbitrarily, but such a limit must be enforced in order to eliminate samples with an insufficient number of observations for which the test results (SPA p-value) would not have adequate statistical power. The 65 -day limit roughly equals three months of trading data, this in turn representing approximately $25 \%$ of trading days in one year. Given this rule, 458 valid subsample windows (combinations of companies and years) are investigated.

\section{Results}

Here we start by presenting and interpreting the results obtained when testing the 44 indicators separately. Then we move to the complete 686,243 rule universe. The third subsection is dedicated to investigating what are the determinants of investor success in the stock market, while the final subsection investigates what are the economic variables that influence market efficiency in Romania. Note that only a summary of the positive discoveries is presented due to ergonomic constraints. For detailed results, please contact the author.

\subsection{Results for the Individual 44 Indicators}

As there are 44 trading rule universes, and for each one a total of 458 sample window are examined, a total of 20,152 results are produced. From these, the SPA test rejects the null hypothesis of no superior predictive ability in 476 cases. Weak statistical significant results, with p-values of up to 0.1 , are also classified as positive discoveries. A summary of those, aggregated by sample window, is presented in Table 2. The first column represents the sample window (combination of a company and year), the second column represents the total number of tests performed for that window, which is equal to the number of indicators, the third column represents the number of trading universes for which at least one specific trading rule has superior predictive ability over the buy and hold benchmark model, the fourth column computes the success rate, while the final three columns display the results for the best trading rule in the given sample window.

Table 2. Positive discoveries, grouped by sample window, when testing individual indicators

\begin{tabular}{|c|c|c|c|c|c|c|}
\hline $\begin{array}{l}\text { Sample } \\
\text { Window }\end{array}$ & Total results & $\begin{array}{l}\text { Number of } \\
\text { positive } \\
\text { results }\end{array}$ & $\begin{array}{l}\text { Positive results } \\
\text { as percent of } \\
\text { total }\end{array}$ & $\begin{array}{l}\text { Average } \\
\text { return }\end{array}$ & excess & $\begin{array}{l}\text { SPA } \\
\text { p-value }\end{array}$ \\
\hline COTR2008 & 44 & 14 & $31.82 \%$ & $1.1689 \%$ & & 0.0320 \\
\hline IMP2008 & 44 & 28 & $63.64 \%$ & $1.0764 \%$ & & 0.0040 \\
\hline IMP2011 & 44 & 1 & $2.27 \%$ & $0.2988 \%$ & & 0.0940 \\
\hline PREH2008 & 44 & 29 & $65.91 \%$ & $1.1057 \%$ & & 0.0210 \\
\hline PREH2011 & 44 & 3 & $6.82 \%$ & $0.5792 \%$ & & 0.0780 \\
\hline ROALR2008 & 44 & 19 & $43.18 \%$ & $0.6930 \%$ & & 0.0270 \\
\hline ROARS2008 & 44 & 4 & $9.09 \%$ & $0.8263 \%$ & & 0.0550 \\
\hline ROART1996 & 44 & 19 & $43.18 \%$ & $1.2383 \%$ & & 0.0340 \\
\hline ROART1998 & 44 & 1 & $2.27 \%$ & $0.5106 \%$ & & 0.0930 \\
\hline ROART2008 & 44 & 14 & $31.82 \%$ & $0.7660 \%$ & & 0.0130 \\
\hline ROARTE2008 & 44 & 20 & $45.45 \%$ & $0.8056 \%$ & & 0.0250 \\
\hline ROATB1998 & 44 & 8 & $18.18 \%$ & $0.6266 \%$ & & 0.0470 \\
\hline ROATB2008 & 44 & 7 & $15.91 \%$ & $0.6190 \%$ & & 0.0670 \\
\hline ROBCC2008 & 44 & 2 & $4.55 \%$ & $0.4534 \%$ & & 0.0400 \\
\hline ROBIO2008 & 44 & 15 & $34.09 \%$ & $0.6822 \%$ & & 0.0410 \\
\hline ROBRD2008 & 44 & 1 & $2.27 \%$ & $0.4574 \%$ & & 0.0700 \\
\hline ROBRK2008 & 44 & 39 & $88.64 \%$ & $1.1714 \%$ & & 0.0040 \\
\hline
\end{tabular}




\begin{tabular}{llllll}
\hline ROBRK2011 & 44 & 3 & $6.82 \%$ & $0.2454 \%$ & 0.0720 \\
ROCMP2008 & 44 & 35 & $79.55 \%$ & $0.8476 \%$ & 0.0130 \\
ROMPN2005 & 44 & 1 & $2.27 \%$ & $1.2741 \%$ & 0.0810 \\
ROOIL2008 & 44 & 13 & $29.55 \%$ & $0.8001 \%$ & 0.0290 \\
ROOLT1998 & 44 & 33 & $75.00 \%$ & $0.6705 \%$ & 0.0110 \\
ROOLT2008 & 44 & 34 & $77.27 \%$ & $0.8109 \%$ & 0.0050 \\
RORPH2011 & 44 & 1 & $2.27 \%$ & $0.2388 \%$ & 0.0990 \\
RORRC2008 & 44 & 31 & $70.45 \%$ & $0.6277 \%$ & 0.0040 \\
ROSCD2008 & 44 & 2 & $4.55 \%$ & $0.3075 \%$ & 0.0750 \\
ROTEL2008 & 44 & 6 & $13.64 \%$ & $0.4596 \%$ & 0.0370 \\
ROTEL2012 & 44 & 3 & $6.82 \%$ & $0.2147 \%$ & 0.0760 \\
ROTGN2008 & 44 & 2 & $4.55 \%$ & $0.3494 \%$ & 0.0930 \\
ROTLV2008 & 44 & 13 & $29.55 \%$ & $0.5459 \%$ & 0.0150 \\
SIF12008 & 44 & 11 & $25.00 \%$ & $0.7085 \%$ & 0.0370 \\
SIF22008 & 44 & 12 & $27.27 \%$ & $0.8430 \%$ & 0.0440 \\
SIF32008 & 44 & 17 & $38.64 \%$ & $0.7639 \%$ & 0.0200 \\
SIF42008 & 44 & 3 & $6.82 \%$ & $0.4131 \%$ & 0.0680 \\
SIF52008 & 44 & 25 & $56.82 \%$ & $0.6919 \%$ & 0.0160 \\
TUFE2008 & 44 & 7 & $15.91 \%$ & $0.6029 \%$ & 0.0670 \\
\hline
\end{tabular}

For the first row in Table 2, the interpretation is that for the company COTR in the year 2008, the SPA test identifies 14 universes that contain superior predictive ability rules. This means that 14 technical analysis indicators display superior predictive ability over the benchmark trading model, which is equivalent to $31.82 \%$ out of all analyzed indicators. The best result is obtained using the "oversold I" strategy for the 29-day Balance of Market Power (BMP) indicator, which obtained an average daily excess return of $1.1689 \%$. The SPA p-value of 0.0320 enables us to reject the null hypothesis of no superior predictive ability over the buy and hold strategy during this time interval.

The presence of positive discoveries means that superior trading models to the benchmark exist. This in turn means that on the Bucharest Stock Exchange, situations exist when the future price behavior can be anticipated using technical analysis indicators that are calculated solely using historical trading data. Because of this, we can reject the weak form Efficient Market Hypothesis for these situations and conclude that the Romanian stock market shows periodic signs of inefficiency. Having established that, there is a very interesting observation that can be made based on the reported positive discoveries, namely that most of them are grouped in specific time frames. An investigation into this aspect is provided in section 3.3. For now, let us look at the results obtained for the trading universe containing all technical analysis models.

\subsection{Results for the Complete Universe}

The results of the tests conducted using the complete 686,243 rule universe are reported in Table 3. As with the ones above, only positive discoveries are reported. This test shows just how successful would investors using a very large set of technical analysis indicators can be on the Bucharest Stock Exchange, as compared with the previous tests that showed the case of limited investors, ones that only specialize in a single technical analysis indicator.

Table 3. Positive discoveries when testing the complete rule universe

\begin{tabular}{lllllll}
\hline $\begin{array}{l}\text { Sample } \\
\text { Window }\end{array}$ & Total results & $\begin{array}{l}\text { Number } \\
\text { positive } \\
\text { results }\end{array}$ & $\begin{array}{l}\text { of } \\
\text { as pesitive results } \\
\text { total }\end{array}$ & $\begin{array}{l}\text { Average } \\
\text { return }\end{array}$ & excess & $\begin{array}{l}\text { SPA } \\
\text { p-value }\end{array}$ \\
\hline ROBRK2008 & 44 & 1 & $2.27 \%$ & $0.9351 \%$ & 0.0450 \\
\hline
\end{tabular}

As only one rule universe is employed, the number of test results equals that of the sample windows. We see that by using a very complex trading universe, in only 1 out of 458 cases does the SPA identify trading models that are superior to the benchmark buy and hold strategy for the Romanian stock market when using daily data. This is very counterintuitive, as common sense tells us that more sophisticated investors, that use a diverse and complex arsenal of investment tools, should be more successful than limited investors that use simpler strategies. The most probable explanation for this phenomenon is a large data snooping bias inherent in a very complex trading universe. It may be 
that model multicollinearity is present and significant for this kind of universe, given that all the indicators are composed using the same basic historical trading observations of open, high, low and close prices plus the trading volume. This obstructs the discovery of true superior predictive models and shows us that investors that use a large arsenal of technical analysis investment techniques are not necessarily the smarter ones.

\subsection{Initial Investigations on Why the Market Is Inefficient}

We return to the results obtained when testing the 44 individual indicators and further analyze them. We can see in Table 2 that many of the positive results are grouped in specific time intervals. To get a clearer view of this phenomenon, Table 4 reports the positive discoveries grouped by sample year, and also the results of a linear regression with dummy variables performed using all 20,152 test observations, where each dummy represents a single year. In essence, the estimated regression coefficients in the dummy regression represent the average SPA p-value obtained for each year.

Table 4. Results by sample year, when testing individual indicators

\begin{tabular}{|c|c|c|c|c|c|}
\hline \multirow[b]{3}{*}{ Year } & \multirow[b]{3}{*}{ Observations } & \multirow{2}{*}{$\begin{array}{l}\text { Positive } \\
\text { summary }\end{array}$} & \multirow{2}{*}{ discoveries } & \multicolumn{2}{|c|}{$\begin{array}{l}\text { Results of linear } \\
\text { regression with dummy } \\
\text { variables }\end{array}$} \\
\hline & & & & \multirow[b]{2}{*}{ Coefficient } & \multirow[b]{2}{*}{ t-stat } \\
\hline & & Total & Success rate & & \\
\hline 1996 & 43 & 17 & $39.53 \%$ & 0.1328 & 3.82 \\
\hline 1997 & 43 & 0 & $0.00 \%$ & 0.7869 & 22.64 \\
\hline 1998 & 387 & 42 & $10.85 \%$ & 0.5976 & 51.58 \\
\hline 1999 & 559 & 0 & $0.00 \%$ & 0.8322 & 86.33 \\
\hline 2000 & 860 & 0 & $0.00 \%$ & 0.8675 & 111.62 \\
\hline 2001 & 989 & 0 & $0.00 \%$ & 0.8483 & 117.06 \\
\hline 2002 & 989 & 0 & $0.00 \%$ & 0.8636 & 119.17 \\
\hline 2003 & 1032 & 0 & $0.00 \%$ & 0.8679 & 122.34 \\
\hline 2004 & 1118 & 0 & $0.00 \%$ & 0.8562 & 125.62 \\
\hline 2005 & 1290 & 1 & $0.08 \%$ & 0.8260 & 130.17 \\
\hline 2006 & 1376 & 0 & $0.00 \%$ & 0.8583 & 139.70 \\
\hline 2007 & 1505 & 0 & $0.00 \%$ & 0.8625 & 146.81 \\
\hline 2008 & 1548 & 399 & $25.78 \%$ & 0.3097 & 53.46 \\
\hline 2009 & 1505 & 0 & $0.00 \%$ & 0.8421 & 143.35 \\
\hline 2010 & 1548 & 0 & $0.00 \%$ & 0.8416 & 145.29 \\
\hline 2011 & 1677 & 7 & $0.42 \%$ & 0.7626 & 137.02 \\
\hline 2012 & 1634 & 3 & $0.18 \%$ & 0.7747 & 137.41 \\
\hline 2013 & 1591 & 0 & $0.00 \%$ & 0.8284 & 144.99 \\
\hline
\end{tabular}

It is very interesting to see that the positive results are concentrated in 1996, 2008 and 1998, while for other years the success rates are insignificant. Also, the regression coefficients are significantly different in those years versus the rest. This means that the predictive ability of technical analysis is dependent upon specific market conditions in certain time frames. What is so special about those intervals that determine the markets to behave inefficiently? An answer is provided in the next section. Note that the results also indicate that the market efficiency in Romania is not improving, but rather varies trough time in a form consistent with the Adaptive Market Hypothesis (AMH) of Lo (2004). Moving forward, table 5 takes the same results and aggregates them by company. 
Table 5. Results by company, when testing individual indicators

\begin{tabular}{|c|c|c|c|c|c|}
\hline \multirow[b]{3}{*}{ Company } & \multirow[b]{3}{*}{ Observations } & \multirow{2}{*}{$\begin{array}{l}\text { Positive } \\
\text { summary }\end{array}$} & \multirow[t]{2}{*}{ discoveries } & \multicolumn{2}{|c|}{$\begin{array}{lcr}\text { Results } & \text { of } & \text { linear } \\
\text { regression } & \text { with } & \text { dummy } \\
\text { variables } & & \\
\end{array}$} \\
\hline & & & & & \\
\hline & & Total & Success rate & Coefficient & t-stat \\
\hline COTE & 387 & 0 & $0.00 \%$ & 0.8087 & 58.85 \\
\hline COTR & 301 & 14 & $4.65 \%$ & 0.7361 & 47.24 \\
\hline ELGS & 344 & 0 & $0.00 \%$ & 0.8316 & 57.05 \\
\hline FP & 129 & 0 & $0.00 \%$ & 0.6766 & 28.42 \\
\hline IMP & 688 & 29 & $4.22 \%$ & 0.7549 & 73.24 \\
\hline PREH & 516 & 30 & $5.81 \%$ & 0.7482 & 62.87 \\
\hline ROALR & 688 & 19 & $2.76 \%$ & 0.7494 & 72.71 \\
\hline ROAPC & 688 & 0 & $0.00 \%$ & 0.8621 & 83.64 \\
\hline ROARS & 602 & 4 & $0.66 \%$ & 0.8351 & 75.79 \\
\hline ROART & 688 & 32 & $4.65 \%$ & 0.7298 & 70.80 \\
\hline ROARTE & 473 & 20 & $4.23 \%$ & 0.7993 & 64.30 \\
\hline ROATB & 688 & 15 & $2.18 \%$ & 0.7766 & 75.34 \\
\hline ROBCC & 387 & 2 & $0.52 \%$ & 0.7479 & 54.42 \\
\hline ROBIO & 602 & 15 & $2.49 \%$ & 0.8294 & 75.27 \\
\hline ROBRD & 559 & 1 & $0.18 \%$ & 0.7545 & 65.98 \\
\hline ROBRK & 344 & 42 & $12.21 \%$ & 0.6884 & 47.23 \\
\hline ROBVB & 129 & 0 & $0.00 \%$ & 0.6729 & 28.26 \\
\hline ROCMP & 688 & 35 & $5.09 \%$ & 0.7636 & 74.08 \\
\hline ROELMA & 602 & 0 & $0.00 \%$ & 0.8171 & 74.16 \\
\hline ROMPN & 430 & 1 & $0.23 \%$ & 0.8210 & 62.97 \\
\hline ROOIL & 645 & 13 & $2.02 \%$ & 0.7874 & 73.97 \\
\hline ROOLT & 645 & 67 & $10.39 \%$ & 0.7616 & 71.54 \\
\hline ROPTR & 602 & 0 & $0.00 \%$ & 0.7988 & 72.49 \\
\hline RORPH & 129 & 1 & $0.78 \%$ & 0.6894 & 28.96 \\
\hline RORRC & 387 & 31 & $8.01 \%$ & 0.7679 & 55.87 \\
\hline ROSCD & 645 & 2 & $0.31 \%$ & 0.8003 & 75.18 \\
\hline ROSNP & 516 & 0 & $0.00 \%$ & 0.8350 & 70.16 \\
\hline ROSOCP & 602 & 0 & $0.00 \%$ & 0.7909 & 71.78 \\
\hline ROTEL & 301 & 8 & $2.66 \%$ & 0.7367 & 47.28 \\
\hline ROTGN & 258 & 2 & $0.78 \%$ & 0.7359 & 43.72 \\
\hline ROTLV & 688 & 12 & $1.74 \%$ & 0.8005 & 77.66 \\
\hline ROVNC & 344 & 0 & $0.00 \%$ & 0.8406 & 57.67 \\
\hline SIF1 & 602 & 11 & $1.83 \%$ & 0.8014 & 72.73 \\
\hline SIF2 & 602 & 12 & $1.99 \%$ & 0.7841 & 71.16 \\
\hline SIF3 & 602 & 17 & $2.82 \%$ & 0.8047 & 73.03 \\
\hline SIF4 & 602 & 3 & $0.50 \%$ & 0.8278 & 75.13 \\
\hline SIF5 & 602 & 24 & $3.99 \%$ & 0.8006 & 72.66 \\
\hline STIB & 430 & 0 & $0.00 \%$ & 0.7744 & 59.40 \\
\hline TUFE & 559 & 7 & $1.25 \%$ & 0.8018 & 70.12 \\
\hline
\end{tabular}

Note: Adjusted R-squared $=0.0201$, Durbin-Watson stat $=1.7494$, Akaike info. criterion $=0.2237$

We see that the success rates and estimated regression coefficients are smoother across companies. This means that the predictive ability of technical analysis indicators is not influenced by specific trading conditions for individual companies. In other words, a trader's potential ability to gain abnormal profit does not depend on the company he/she invests in on the Romanian stock market. Next, table 6 aggregates the results by technical analysis indicator. 
Table 6. Results by technical analysis indicator, when testing individual indicators

\begin{tabular}{|c|c|c|c|c|c|}
\hline \multirow[b]{3}{*}{ Indicator } & \multirow[b]{3}{*}{$\begin{array}{r}\text { Observati } \\
\text { ons }\end{array}$} & \multirow{2}{*}{\multicolumn{2}{|c|}{$\begin{array}{l}\text { Positive discoveries } \\
\text { summary }\end{array}$}} & \multicolumn{2}{|c|}{$\begin{array}{l}\text { Results of linear regression } \\
\text { with dummy variables }\end{array}$} \\
\hline & & & & \multirow[b]{2}{*}{ Coefficient } & \multirow[b]{2}{*}{ t-stat } \\
\hline & & Total & $\begin{array}{r}\text { Success } \\
\text { rate }\end{array}$ & & \\
\hline Filter \& ConsecutiveWL & 458 & 21 & $4.59 \%$ & 0.7010 & 59.46 \\
\hline PI Opinion Oscillator & 458 & 11 & $2.40 \%$ & 0.8295 & 70.36 \\
\hline Rate of Change & 458 & 9 & $1.97 \%$ & 0.8627 & 73.18 \\
\hline Stochastic & 458 & 14 & $3.06 \%$ & 0.8267 & 70.12 \\
\hline $\begin{array}{l}\text { Directional movement (PDM vs MDM) } \\
\text { crossover }\end{array}$ & 458 & 12 & $2.62 \%$ & 0.8267 & 70.12 \\
\hline Relative Strength Index & 458 & 15 & $3.28 \%$ & 0.7856 & 66.64 \\
\hline Moving Average Convergence Divergence & 458 & 4 & $0.87 \%$ & 0.8652 & 73.38 \\
\hline Commodity Channel Index & 458 & 10 & $2.18 \%$ & 0.7934 & 67.30 \\
\hline TRIX momentum & 458 & 16 & $3.49 \%$ & 0.8176 & 69.35 \\
\hline Detrend Price Oscillator & 458 & 4 & $0.87 \%$ & 0.8812 & 74.74 \\
\hline Arms Ease of Movement & 458 & 3 & $0.66 \%$ & 0.6618 & 56.13 \\
\hline Bollinger oscillator & 458 & 19 & $4.15 \%$ & 0.8112 & 68.80 \\
\hline Ultimate Oscillator & 458 & 10 & $2.18 \%$ & 0.8397 & 71.22 \\
\hline True Strength Index & 458 & 18 & $3.93 \%$ & 0.7797 & 66.13 \\
\hline Random Walk Index & 458 & 5 & $1.09 \%$ & 0.8474 & 71.87 \\
\hline Know Sure Thing & 458 & 6 & $1.31 \%$ & 0.8725 & 74.01 \\
\hline Relative Momentum Index & 458 & 18 & $3.93 \%$ & 0.7990 & 67.77 \\
\hline Stochastic Momentum Index & 458 & 14 & $3.06 \%$ & 0.8222 & 69.74 \\
\hline Chande Momentum Oscillator & 458 & 12 & $2.62 \%$ & 0.8180 & 69.38 \\
\hline Dynamic Momentum Index & 458 & 10 & $2.18 \%$ & 0.8546 & 72.49 \\
\hline Polarized Fractal Efficiency & 458 & 19 & $4.15 \%$ & 0.8273 & 70.17 \\
\hline Stochastic RSI Oscillator & 458 & 13 & $2.84 \%$ & 0.8047 & 68.25 \\
\hline The Quantitative Candlestick & 458 & 4 & $0.87 \%$ & 0.6419 & 54.44 \\
\hline Relative Volatility Index & 458 & 13 & $2.84 \%$ & 0.8165 & 69.26 \\
\hline New Relative Volatility Index & 458 & 19 & $4.15 \%$ & 0.7915 & 67.14 \\
\hline Inertia Indicator & 458 & 9 & $1.97 \%$ & 0.8287 & 70.29 \\
\hline Balance of Market Power & 458 & 17 & $3.71 \%$ & 0.8111 & 68.80 \\
\hline Center of Gravity Oscillator & 458 & 6 & $1.31 \%$ & 0.7284 & 61.79 \\
\hline Relative Vigor Index & 458 & 11 & $2.40 \%$ & 0.8141 & 69.05 \\
\hline Vortex Oscillator & 458 & 16 & $3.49 \%$ & 0.8295 & 70.36 \\
\hline Accumulation Swing Index & 458 & 23 & $5.02 \%$ & 0.4514 & 38.29 \\
\hline Chaikin Money Flow & 458 & 12 & $2.62 \%$ & 0.8395 & 71.21 \\
\hline Chaikin Oscillator & 458 & 7 & $1.53 \%$ & 0.7994 & 67.81 \\
\hline Market Volume Impact & 458 & 3 & $0.66 \%$ & 0.8095 & 68.67 \\
\hline Demand Index & 458 & 18 & $3.93 \%$ & 0.7996 & 67.83 \\
\hline Money Flow Index & 458 & 13 & $2.84 \%$ & 0.8330 & 70.66 \\
\hline Klinger Volume Oscillator & 458 & 1 & $0.22 \%$ & 0.8684 & 73.66 \\
\hline Kase PeakOscillator & 458 & 4 & $0.87 \%$ & 0.8698 & 73.78 \\
\hline Kase Convergence Divergence & 458 & 5 & $1.09 \%$ & 0.8527 & 72.33 \\
\hline Aroon Oscillator momentum & 458 & 17 & $3.71 \%$ & 0.8047 & 68.25 \\
\hline Linear Regression Slope & 458 & 7 & $1.53 \%$ & 0.7927 & 67.24 \\
\hline $\begin{array}{lll}\text { Williams } & \text { Variable } & \text { Accumulation } \\
\text { Distribution } & & \end{array}$ & 458 & 1 & $0.22 \%$ & 0.4875 & 41.34 \\
\hline On Balance Volume & 458 & 0 & $0.00 \%$ & 0.4123 & 34.97 \\
\hline
\end{tabular}


The success rates are also smooth across indicators. We can also see that all but one indicator manage to exhibit superior predictive ability in at least one year in the recent history of the stock market in Romania. Because of this, one might think that a trader's ability of generating abnormal returns does not depend on any specific technical analysis prediction model. However, the regression coefficients point out a handful of indicators that consistently manage to outperform the rest, with the Accumulation Swing Index being the best among the bunch. This, in the context of the estimated goodness of fit measurements, points out that a trader's ability of generating abnormal returns slightly depends on the implemented prediction model.

It is also interesting to note that the one indicator that does not generate a single case of superior predictive ability is the On Balance Volume, the earliest and most well-known money flow indicator. This can signify one of two things: either it has no economic validity, either it is so extensively used by investors in Romania that is incorporated efficiently into trading prices.

\subsection{Determining Factors for Market Efficiency in Romania}

This analysis is conducted only for the results obtained when testing the 44 individual indicators. Tests for the complete rule universe are also carried out but are not reported here, since the conclusions do not substantially differ. Two factors that could influence informational efficiency are taken into consideration, namely liquidity and price momentum. Two distinct indicators are used for market liquidity, a volume-related one in the form of the percent of traded capitalization (ptc) and a time-related one in the form of the relative number of trading days (ntd), while the yearly log-return is used as the measure for price momentum. We chose liquidity as an explanation factor because it proxies the general level of market development, this being a candidate explanation factor for the level of efficiency. The more developed (mature) a market is (more transparent and more stable from an economic, social, legal or political view), the more liquid it should be. On the other hand, we chose price momentum because it can be considered as a proxy for investor behavior. In order to understand why it is so, note that the return is basically a function of information and investor behavior. When new information arrives in the market, the investors interpret it and act upon market prices, thus moving the overall return in one direction or another. If the investors are fully rational (as hypothesized by the EMH), then they will perfectly incorporate the information, this leading to returns that are impossible to forecast by models that rely only on past trading data (such is the case with technical analysis indicators). But if this is not the case (our earlier tests proved that we can anticipate future returns using past trading data), it means that not all publicly available information was incorporated into trading prices. This, in turn, points to suboptimal investor behavior, which, as explained by the Behavior Finance literature, mostly means overreaction to information. If this is the case, we should discover a statistical significant relationship between specific aggregate returns and the level of market efficiency (which is proxyed by the SPA p-values).

Three distinct equations are used to model each relationship. The first one is a simple linear regression, which is defined as:

$$
p_{S P A}=\alpha+\beta x+\varepsilon
$$

where $x$ is the normalized independent variable used to explain the variation in the SPA p-value, $\beta$ is its linear coefficient, $\alpha$ is the intercept and $\varepsilon$ is an independent and identical distributed error term. The second equation is derived from the GLM specification, using the Binomial Proportion as the conditional distribution of the response variable and the Logit link function. As a result, the model is defined as:

$$
p_{S P A}=\frac{1}{1+e^{-(\beta x+\varepsilon)}}
$$

Because the SPA p-values can also be intuitively transformed into a binary variable, the third equation is a standard logistic regression, which is defined as:

$$
p_{S P A}^{b}=\frac{1}{1+e^{-(\beta x+\varepsilon)}}
$$

where the $b$ superscript used for the dependent variable denotes that it is a binary variable based on the SPA p-value obtained using the following transformation: $p_{S P A}^{b}=1_{\left\{p_{S P A}>0.1\right\}}$. As a consequence, the dependent variable in the logistic model is zero when the SPA test rejects the null (a positive discovery) and one otherwise.

Table 7 presents the estimated regression models, together with the results of the relevant hypothesis tests. Also, a visual representation of the relationships plus the model fits are presented in Figure 1. Note that there are 9 regressions performed in total, but 2 are dropped from Table 7 because of a negative adjusted $R^{2}$. Also note that the 
linear model where the price momentum is the independent variable presents two important structural breaks, as revealed by the Chow breakpoint test. This is also evident when looking at figure 1c (green line). As a result, the equation is split over three distinct subsamples, with the results of the equation for the first subsample (first 93 observations) being included in the last column of Table 7.
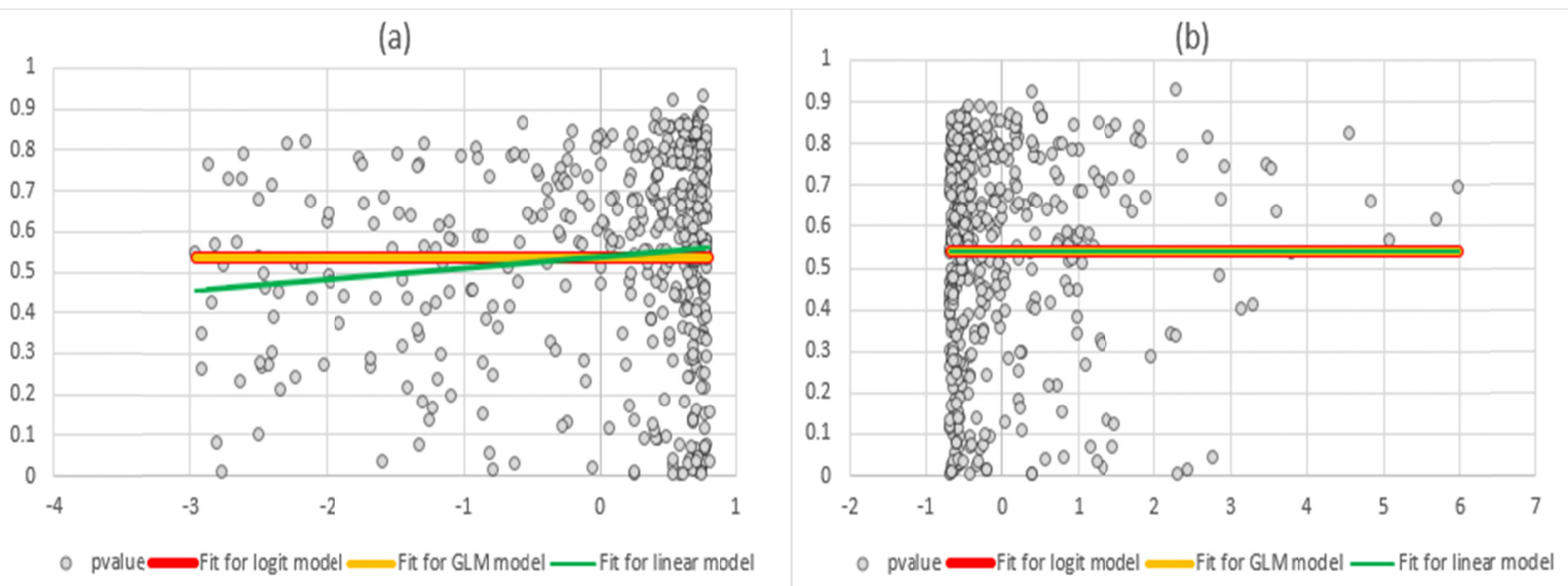

(c)

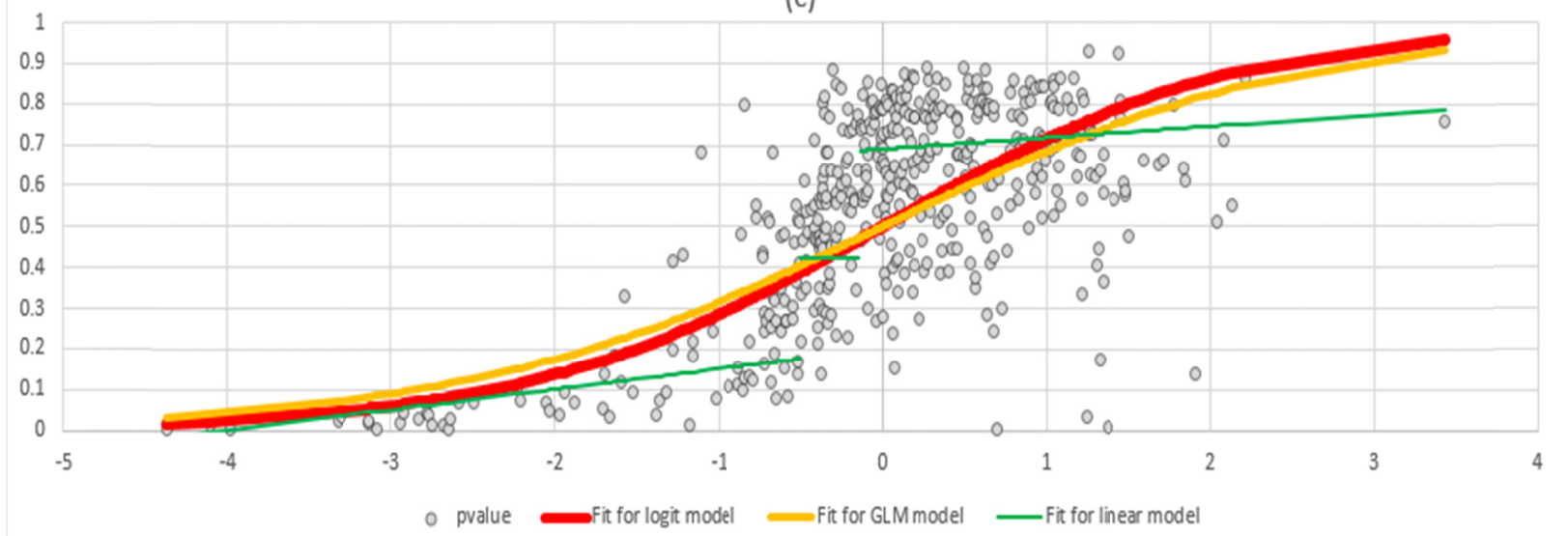

Figure 1. Scatter plot representation and fitted values of the regression models

Description: The normalized independent variable are plotted on the x-axis, while the SPA p-value on the y-axis:

(a) P-value plotted vs. the relative number of trading days as the independent variable

(b) P-value plotted vs. the relative turnover as the independent variable

(c) P-value plotted vs. the annualized log-return as the independent variable

Table 7. Regression results

\begin{tabular}{lcccccccc}
\hline $\begin{array}{l}\text { Model type } \\
\text { Independent variable (x) }\end{array}$ & $\begin{array}{c}\text { Linear } \\
\text { ntd }\end{array}$ & $\begin{array}{c}\text { Logistic } \\
\text { ntd }\end{array}$ & $\begin{array}{c}\text { Linear } \\
\text { pct }\end{array}$ & $\begin{array}{c}\text { Logistic } \\
\text { pct }\end{array}$ & $\begin{array}{c}\text { Linear } \\
\text { ret }\end{array}$ & $\begin{array}{c}\text { Logistic } \\
\text { ret }\end{array}$ & $\begin{array}{c}\text { GLM } \\
\text { ret }\end{array}$ & $\begin{array}{c}\text { Linear } \\
\text { ret } 1 . .93\end{array}$ \\
\hline$\alpha$ & 0.5374 & & 0.5374 & & 0.5374 & & & 0.2018 \\
& $(0.00)$ & & $(0.00)$ & & $(0.00)$ & & & $(0.00)$ \\
$\beta$ & 0.0276 & -0.0739 & 0.0140 & -0.0125 & 0.1573 & 0.9188 & 0.7744 & 0.0505 \\
& $(0.01)$ & $(0.43)$ & $(0.22)$ & $(0.89)$ & $(0.00)$ & $(0.00)$ & $(0.00)$ & $(0.00)$ \\
F-stat & 5.83 & & 1.47 & & 318.71 & & & 59.58 \\
& $(0.01)$ & & $(0.22)$ & & $(0.00)$ & & & $(0.00)$ \\
Log likelihood & -2.73 & -317.1 & -4.90 & -317.4 & 115.73 & -285.0 & -208.4 & 105.16 \\
Akaike Info.Criterion & 0.0207 & 1.3893 & 0.0301 & 1.3906 & -0.496 & 1.2493 & 0.9147 & -2.2184 \\
Adjusted R ${ }^{*}$ & 0.0105 & & 0.0010 & & 0.4101 & & 0.3830 & 0.3890
\end{tabular}




\begin{tabular}{|c|c|c|c|c|c|c|c|c|}
\hline Hosmer-Lemeshow statistic & & \multicolumn{2}{|l|}{$\begin{array}{c}317.73 \\
(0.00)\end{array}$} & \multicolumn{2}{|l|}{$\begin{array}{c}317.03 \\
(0.00)\end{array}$} & $\begin{array}{c}370.41 \\
(0.00)\end{array}$ & & \\
\hline Andrews statistic & & $\begin{array}{c}320.05 \\
(0.00)\end{array}$ & & $\begin{array}{c}317.68 \\
(0.00)\end{array}$ & & $\begin{array}{c}380.20 \\
(0.00)\end{array}$ & & \\
\hline Jarque-Bera statistic & $\begin{array}{l}39.89 \\
(0.00)\end{array}$ & $\begin{array}{c}1542.91 \\
(0.00)\end{array}$ & $\begin{array}{l}37.01 \\
(0.00)\end{array}$ & $\begin{array}{c}1565.74 \\
(0.00)\end{array}$ & $\begin{array}{l}25.99 \\
(0.00)\end{array}$ & $\begin{array}{c}622.60 \\
(0.00)\end{array}$ & $\begin{array}{l}67.64 \\
(0.00)\end{array}$ & $\begin{array}{l}13.78 \\
(0.00)\end{array}$ \\
\hline Durbin-Watson statistic & 0.0254 & & 0.0067 & & 0.6687 & & & 0.7255 \\
\hline Breusch-Pagan-Godfrey statistic & $\begin{array}{c}4.7354 \\
(0.02) \\
\end{array}$ & & $\begin{array}{c}0.0289 \\
(0.86) \\
\end{array}$ & & $\begin{array}{c}8.6560 \\
(0.00) \\
\end{array}$ & & & $\begin{array}{c}23.1716 \\
(0.00) \\
\end{array}$ \\
\hline $\begin{array}{l}\text { Discription: }{ }^{1} \text { All regressions } \\
\text { deviation of the original varial } \\
{ }^{2} \text { P-values in pare } \\
{ }^{*} \text { The adjusted R- } \\
\text { D1 is the residual deviance fo } \\
\text { a regression constant. }\end{array}$ & $\begin{array}{l}\text { erform } \\
\text { eing rep } \\
\text { is. } \\
\text { ed for } \\
\text { model }\end{array}$ & $\begin{array}{l}\text { d using no } \\
\text { orted in th } \\
\text { he GLM } \\
\text { question }\end{array}$ & $\begin{array}{l}\text { rmalized } \\
\text { bottom } \\
\text { nodels is } \\
\text { and D0 }\end{array}$ & $\begin{array}{l}\text { section o } \\
\text { a pseud } \\
\text { s the resi }\end{array}$ & $\begin{array}{l}\text { nt vari } \\
\text { the tabl } \\
\text { R-squa } \\
\text { dal dev }\end{array}$ & $\begin{array}{l}\text { d calcu } \\
\text { nce for }\end{array}$ & $\begin{array}{l}\text { ed as } 1 \\
\text { mode }\end{array}$ & $\begin{array}{l}\text { id standar } \\
\text { Do, wher } \\
\text { uding onl }\end{array}$ \\
\hline
\end{tabular}

The results indicate that there is almost no relationship between the degree of market liquidity and the degree of market efficiency. The estimated coefficient is significant only for the linear model with the relative number of trading days as the explanatory variable. It is very surprisingly to see that, as shown by the estimated coefficients and diagnostic tests, the relationship is very weak, this contradicting economic common-sense, as general market conditions, as proxied by liquidity, should have an impact on efficiency. In the end, the results show that the general market conditions have a nearly insignificant impact on market efficiency for the Romanian stock market.

Moving to the equations for which the price momentum is used to model market efficiency, several very interesting conclusions can be extracted. We see that the SPA p-values can be explained using the yearly price returns of the tested stocks, using a variety of specifications. The relationship is positive and robust, as shown by the goodness of fit test statistics. This means that the more the price declines in a year, the more significant the predictive ability of technical analysis indicators gets and the less efficient the market is. This implies that investors on the Romanian stock market have a tendency to overreact to severe negative information. This implies that in very stressful periods they display signs of panic. Although other behavioral biases can be invoked, there is sufficient evidence to conclude that irrational investor behavior can lead to negative price movements inconsistent with the Efficient Market Hypothesis in Romania.

Further, by using the estimated model coefficients, an exact quantitative threshold can be calculated in order to characterize the efficient nature of price movements and investor rationality. When we substitute 0.1 for the dependent variable (Note 3) and solve for the independent variable, the linear model predicts a threshold log-return of $-132.09 \%$, the logistic model predicts a threshold log-return of $-159.66 \%$, while the GLM model predicts a threshold log-return of $-192.38 \%$. This translates into discrete returns of $-73.31 \%,-79.74 \%$ and $-85.39 \%$, respectively. Consequently, yearly returns that are lower than $-70 \%$ can be considered a result of an inefficient information aggregation process. This conclusion arises because for such price movements, technical analysis trading rules that display superior predictive ability to the benchmark buy and hold model can be found. Considering that market efficiency is directly influenced by investor behavior, this is a very significant finding, as a quantitative threshold that describes investor rationality on the Romanian stock market is established.

\section{Conclusions}

This paper tries to evaluate the weak form Efficient Market Hypothesis on the Romanian stock market by investigating the predictive ability of 44 different momentum and money flow technical analysis indicators, combined in 5 different investment strategies on daily historical data of 39 stocks listed on the Bucharest Stock Exchange.

The Superior Predictive Ability test of Hansen (2005) is used to test for the null hypothesis that the best model in a rule universe has no predictive superiority over the buy-and-hold strategy. Separate tests are conducted for each indicator and for the complete universe of 686,243 rules.

Several cases of predictive ability after adjusting for trading costs are uncovered when testing each indicator individually, but the positive discoveries greatly diminishes when employing the complete rule universe. This shows that the weak form Efficient Market Hypothesis does not always hold on the Romanian stock market and investors 
have the opportunity to gain abnormal profits from time to time. The results are consistent with the Adaptive Market Hypothesis of Lo (2004).

When looking for explanations as to what influences investor success, we show that it has nothing to do with specific listed companies, slightly depends on the prediction models used, it is negatively influenced by the quantity of implemented prediction models and it is highly influenced by the market conditions and dynamics in specific time intervals.

We then try to explain the market efficiency discrepancies, using linear, logistic and GLM regressions. We determine that general market conditions, as proxyed by market liquidity, have a very weak impact on efficiency, while specific events and investor behavior, as proxyed by price momentum, is its main determinant. We show that the more severe a downtrend is, the more predictive power do technical analysis indicators have and, thus, the less efficient the market is. This indicates that investor overreact to severe negative events, which means that they sometimes display signs of panic. Using the estimated model parameters, we can estimate that any price decline of more than $-70 \%$ in a single year is evidence of suboptimal activity. This is a very interesting conclusion, as a quantitative threshold can be established in order to characterize investor rationality on the Romanian stock market.

\subsection{Limitations and Points of Interest for Future Research}

Although this paper provides an important contribution to the efficient market literature in Romania, it still has several limitations, these mainly coming from methodological and data constraints. First, because all window length parameters of technical analysis indicators are restricted to a maximum of 43, it means that the maximum lookback period is only two months. The problem with larger lookback windows is that it would greatly expand the rule universe, thus increasing the test computing time to inconvenient levels. Although Menkhoff (2010) showed that investors that use technical analysis have a shorter investment horizon and, as a consequence, utilize a shorter lookback period, two months may still be too short. Defining a lookback period that would get closer to what practitioners actually use would be an improvement.

Second, a significant limitation is the absence of some other categories of prediction models from the rule universe, such as volume, volatility or market sentiment technical analysis indicators. Also, the addition of indicators based on fundamental analysis, that rely on historical financial data, would get us close to evaluating the degree in which most of the public available information is incorporated into trading prices. Nevertheless, the diversity of the employed universe is as high as it gets for current financial research, even by international standards. For example, in a test of the US financial markets using the RC and SPA tests, Neuhierl and Schlusche (2011) used 10,256 rules for their largest universe.

Finally, there is a limitation caused by the sample data. Because only daily data is used, the conclusions are only valid in this specification. The addition of intraday data would be very interesting. Also, the 39 selected companies are only a portion of the total listings on the Bucharest Stock Exchange and are all currently traded. This limits the applicability of the conclusions to other issuers and, more seriously, could introduce a survivorship bias for the reported results. In this latter aspect, the addition of some delisted companies would improve the significance of the conclusions.

\section{Acknowledgements}

The authors thank Prof. Victor Dragota for the many valuable comments he made regarding an initial draft of the paper. We also thank the entire team that implemented the PROFIN project at the Bucharest University of Economic Studies, which enabled us to have access to the Thomson Reuters Eikon platform for collecting our data.

\section{References}

Anghel, D. G. (2013a). The Performance of ROC on the BSE. Theoretical and Applied Economics, 3(3(580)(supplement)), 373-379.

Anghel, D. G. (2013b). How Reliable is the Moving Average Crossover Rule for an Investor on the Romanian Stock Market?. The Review of Finance and Banking, 5(2), 89-115.

Colby, R. W. (2002). The Encyclopedia of Technical Market Indicators (2 ${ }^{\text {nd }}$ ed.). New York: McGraw-Hill.

Corradi, V., \& Swanson, N. R. (2013). A Survey of Recent Advances in Forecast Accuracy Comparison Testing, with an Extension to Stochastic Dominance. In Chen, X. and Swanson N. R. (Eds.), Recent Advances and Future Directions in Causality, Prediction, and Specification Analysis (pp.121-143). New York: Springer. http://dx.doi.org/10.1007/978-1-4614-1653-1_5 
Dragotă, V., Căruntu, M., \& Stoian, A. (2008). An Analysis of Closed-end Fund Puzzle for Emerging Capital Markets. Theoretical and Applied Economics, 10, 53-60.

Dragota, V., \& Oprea, D. S. (2014). Informational Efficiency Tests on the Romanian Stock Market: A Review of the Literature. The Review of Finance and Banking, 6(1), 15-28.

Dragotă, V., Stoian, A., Pele, D., Mitrică, E., \& Bensafta, M. (2009). The development of the Romanian capital market: Evidences on information efficiency. Romanian Journal of Economic Forecasting, 10(2), 147-160.

Hall, P., Horowitz J. L., \& Jing, B. Y. (1995). On blocking rules for the bootstrap with dependent data. Biometrika, 82(3), 561-574. http://dx.doi.org/10.1093/biomet/82.3.561

Hansen, P. R. (2005). A Test for Superior Predictive Ability. Journal of Business and Economic Statistics, 23(4), 365-380. http://dx.doi.org/10.1198/073500105000000063

Hsu, P. H., Hsu, Y. C., \& Kuan, C. M. (2010). Testing the predictive ability of technical analysis using a new stepwise test without data snooping bias. Journal of Empirical Finance, 17(3), 471-484. http://dx.doi.org/10.1016/j.jempfin.2010.01.001

Lim, K. P., \& Brooks, R. (2011). The evolution of stock market efficiency over time: a survey of the empirical literature. Journal of Economic Surveys, 25(1), 69-108. http://dx.doi.org/10.1111/j.1467-6419.2009.00611.x

Lo, A. W. (2004). The adaptive markets hypothesis. The Journal of Portfolio Management, 30(5), 15-29. http://dx.doi.org/10.3905/jpm.2004.442611

Menkhoff, L. (2010). The Use of Technical Analysis by Fund Managers: International Evidence. Journal of Banking and Finance, 34(11), 2573-2586. http://dx.doi.org/10.1016/j.jbankfin.2010.04.014

Neuhierl, A., \& Schlusche, B. (2011). Data snooping and market-timing rule performance. Journal of Financial Econometrics, 9(3), 550-587. http://dx.doi.org/10.1093/jjfinec/nbq032

Politis, D. N., \& Romano, J. P. (1994). The stationary bootstrap. Journal of the American Statistical Association, 89(428), 1303-1313. http://dx.doi.org/10.1080/01621459.1994.10476870

Romano, J. P., \& Wolf, M. (2005). Stepwise multiple testing as formalized data snooping. Econometrica, 73(4), 1237-1282. http://dx.doi.org/10.1111/j.1468-0262.2005.00615.x

White, H. (2000). A reality check for data snooping. Econometrica, 68(5), 1097-1126. http://dx.doi.org/10.1111/1468-0262.00152

\section{Notes}

Note 1. Please see Colby (2002) for a detailed explanation about the essence of each type of indicator. Other categories of indicators used by technicians are trend indicators, volume indicators, volatility indicators and sentiment indicators. There are also other technical analysis methods, besides indicators: charting (drawing trend lines, support, and resistance or trend channels), chart patterns, Japanese candlesticks, Elliot waves, Fibonacci retracements, Gann angles and others.

Note 2. Using the Thompson Reuters Eikon trading symbols, the companies are ROART, IMP, ROOLT, ROATB, ROCMP, ROMPN, ROAPC, ROTLV, ROALR, ROARS, ROOIL, ROPTR, ROSCD, ELGS, PREH, ROBIO, ROELMA, ROSOCP, STIB, TUFE, SIF1, SIF2, SIF3, SIF4, SIF5, ROBRD, ROSNP, ROARTE, COTR, RORRC, ROBCC, COTE, ROBRK, ROVNC, ROTEL, ROTGN, ROBVB, RORPH and FP.

Note 3. This value is used because it is the threshold p-value bellow which the SPA null hypothesis is rejected. 